\title{
Degradation of Reactive Blue 19 Dye Using Copper Nanoparticles Synthesized from Labeo rohita Fish Scales: a Greener Approach
}

\author{
Asma Haque ${ }^{1}$, Shumaila Kiran ${ }^{2 *}$, Sofia Nosheen ${ }^{3 * *}$, Gulnaz Afzal ${ }^{4}$, Tahsin Gulzar ${ }^{2}$, \\ Salman Ahmad ${ }^{2}$, Shaifq-ur-Rehman2 ${ }^{2}$, Muhammad Hassan Tariq ${ }^{2}$ \\ ${ }^{1}$ Department of Bioinformatics and Biotechnology, Government College University, Faisalabad, Pakistan \\ ${ }^{2}$ Department of Applied Chemistry, Government College University, Faisalabad, Pakistan \\ ${ }^{3}$ Department of Environmental Science, Lahore College For Women University, Lahore, Pakistan \\ ${ }^{4}$ Department of Zoology, Islamia University, Bahawalpur, Pakistan
}

Received: 22 December 2018

Accepted: 24 February 2019

\begin{abstract}
Our current study deals with the green synthesis of copper nanoparticles using extract of Labeo rohita fish scales. There is no need to add any external reducing and stabilizing agents as the gelatin found in fish scale extract possesses plenty of reducing and stabilizing properties. The synthesized copper nanoparticles (Cu-NPs) were characterized by Zeita sizer and SEM. Cu-NPs were applied to decolorize Reactive Blue 19 dye. Different experimental conditions like concentration of reactive Blue 19 dye, concentration of copper nanoparticles, $\mathrm{pH}$ and temperature were optimized. The degrading potential of copper nanoparticles increased their applicability for the decolorization of Reactive Blue 19 dye. Reactive Blue 19 dye was maximum decolorized (90.18\%) at aconc. of 0.03\%, $4 \mathrm{mg} \mathrm{Cu-NPs,}$ $\mathrm{pH} 10$ at $50^{\circ} \mathrm{C}$. The effectiveness of the method was evaluated by water quality assurance parameters such as total organic carbon (TOC) and chemical oxygen demand (COD). The reaction products were characterized by FTIR spectral studies.
\end{abstract}

Keywords: Labeo rohita scales, Cu-Nanoparticles, SEM, decolorization,COD, FTIR

\section{Introduction}

A number of dyes are employed in the synthesis of various products of commercial value [1]. Even little amounts of dye produce significant color [2], which is undesirable and is problematic in the environment where

*e-mail: shumaila.asimch@gmail.com

**e-mail: nosheen.sofia@yahoo.com it is being disposed of $[3,4]$. These dyes are an alarming threat to aquatic biota [5]. Therefore, dye removal from effluents is needed to safeguard human health and for the preservation and betterment of the natural environment [6-9]. Many physical, chemical and biological methods are in use, but these methods have certain drawbacks. Physical methods convert pollution from liquid form to solid form as sludge [10]. Treatment of industrial wastewater by chemical methods often generates more toxic metabolites/products than their precursors [11]. 
These methods are therefore potentially less efficient for the removal of problematic dyes [12]. Nanotechnology is an emerging technology that plays a significant role in environmental remediation [13]. The use of nanoparticles is gaining more popularity for effective removal of contaminants from wastewater [14]. It is an efficient way to remove a wide variety of toxicants from industrial wastewaters [15]. Synthesis of metallic nanoparticles using waste material offers a promising approach for environmental remediation [16]. The fish-processing industry produces $30-40 \%$ of solid waste [17]. Different methods such as landfilling and incineration are used to get rid of fishery waste [18], which contains a high amount of proteins, oil and chitin [19]. Preparation of nanoparticles via fish scales is a greener approach, being cost-effective and environmentally friendly in nature [20]. Gold-, silver- and platinum-based nanoparticles are found to be effective in removal of contaminants. These metallic nanoparticles are replaced by copper nanoparticles because of easy availability and costeffective nature [21]. The use of copper nanoparticles for organic pollutant degradation was found to be an effective method [22]. Studies demonstrate that metallic nanoparticles are capable of promoting the degradation of dyes, which occurs by reductive [23] or oxidative processes [24]. During reductive processes, the oxidized metal supplies electrons to the dye molecule [25]. Copper nanoparticles can favor the in situ hydrogen peroxide $\left(\mathrm{H}_{2} \mathrm{O}_{2}\right)$ formation in an acidified system by oxi-reduction reactions. In these systems, radicals are formed, which act on the oxidative degradation of organic pollutants like a Fenton-like reaction [26]. The present project was planned to synthesize copper nanoparticles (Cu-NPs) using scales of Labeo rohita. Copper nanoparticles were applied to decolorize the problematic Reactive Blue 19 dye, used on the textile sector for dyeing process. The degradation products were identified by FTIR spectral analysis.

\section{Materials and Methods}

\section{Material}

All chemicals were of analytical grade purchased from Sigma-Aldrich and used as received. Fish scales were taken from a fish market of Faisalabad, Pakistan, cleaned using purified water, ground and dried in an oven at $60^{\circ} \mathrm{C}$. The dried material was sieved and stored.

\section{Preparation of Aqueous Extract of Fish Scales}

The fine powder of $L$. rohita scales $(10 \mathrm{~g})$ were put in flask of $500 \mathrm{~mL}$ distilled water and placed on hot plate for 20 minutes at $70^{\circ} \mathrm{C}$. Hot material was centrifuged at $4000 \mathrm{rpm}$ for 15 minutes. The extract was taken and stored at $4^{\circ} \mathrm{C}$ in a refrigerator [27].

\section{Synthesis of $\mathrm{Cu}$ Nanoparticles (Cu-NPs)}

$10 \mathrm{~mL}$ aqueous solution of copper chloride $(0.1 \mathrm{M})$ was added to $10 \mathrm{~mL}$ fish scale extract $(10 \%)$ and heated for $15 \mathrm{~min}$. at $70^{\circ} \mathrm{C}$ followed by slow cooling to room temperature. The solution was allowed to stabilize for 3 days. Light-brown particles were formed at the bottom of the vessel [8]. The synthesized particles were vacuum filtered, washed with water and ethanol, and finally dried. The particles were stored at $-4^{\circ} \mathrm{C}$ [28].

\section{Characterization of $\mathrm{Cu}-\mathrm{Nanoparticles}(\mathrm{Cu}-\mathrm{NPs})$ via SEM}

The most important parameter for characterization of nanoparticles is their particle size. The sample was taken in glass cuvette and the temperature was $25^{\circ} \mathrm{C}$ and the system was run for 21 seconds. The synthesized nanoparticles were subjected to the spectrophotometer (perfect system spectrophotometer MS-4375) for the UV-Vis absorption spectra, $\lambda_{\max }$ in $\mathrm{nm}$, furnished with quartz cell. The SEM images were documented with the help of a scanning electron microscope (FEI Quanta 400 FEG). The samples were first gold-coated by using a sputter coater, and then obtained the SEM micrograph.

\section{Determining Size Distribution Intensity by Dynamic Light Scattering Method}

Dynamic light scattering capacities (DLS) were determined out on Malvern Zeta sizer (Nano ZS ZEN 3600). The particle size is one of the most important parameters for characterizing nanoparticles. The sample was taken in a glass cuvette and the temperature was set to $25^{\circ} \mathrm{C}$, and the system was run for 21 seconds.

Application of Synthesized Cu-NPs for Decolorization of Reactive Blue 19 Dye

Preparation of Dye Solution

Different concentrations $(0.01 \%, \quad 0.03 \%, \quad 0.05 \%$, $0.07 \%, 0.1 \%$ ) of Reactive Blue 19 dye were prepared and were diluted ten times to scan $\lambda_{\text {max }}$.

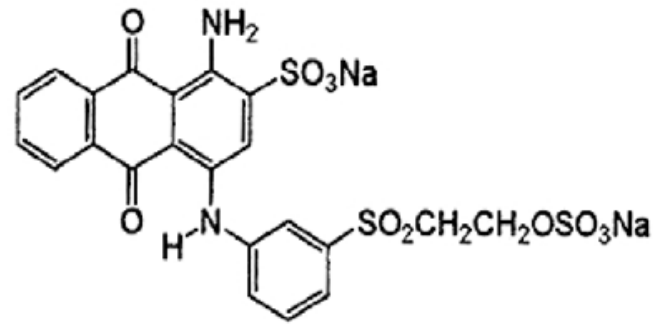

Structure of Reactive Blue 19 dye 


\section{Experimental Procedure}

$5 \mathrm{~mL}$ of dye (Reactive Blue 19$)$ solution $(0.01 \%)$ was diluted up to $50 \mathrm{~mL}$. pH of solution was maintained to 6 and $1 \mathrm{mg}$ of $\mathrm{Cu}-\mathrm{NPs}$ were added to it. The reaction was let to run at $30^{\circ} \mathrm{C}$ for a period of $75 \mathrm{~min}$. Same experiments were done with other concentrations $(0.03$, $0.05,0.07$ and $0.1 \%$ ) of Reactive Blue 19 dye solution. In order to optimize $\mathrm{Cu}-\mathrm{NP}$ concentration, different concentrations of Cu-NPs (1-5 mg/50 mL of dye solution) were taken. Different $\mathrm{pH}$ (4-12) values were optimized using the same methodology. Different temperatures $\left(30-70^{\circ} \mathrm{C}\right)$ were also optimized. The experiments were run following the same methodology described above. One parameter was varied at a time while keeping others constant [29].

\section{Chemical Analysis}

The progress of the reaction was checked by measuring absorbance at $425 \mathrm{~nm}$ using a UV-visible spectrophotometer (perfect system spectrophotometer MS-4375) after every 15 minutes. Decolorization (\%) was calculated by the formula given below:

$$
\text { Decolorization }(\%)=(\mathrm{I}-\mathrm{F}) / \mathrm{I} \times 100
$$

...where $\mathrm{I}$ is the initial absorbance and $\mathrm{F}$ is the final absorbance of decolorized or treated dye solution.

\section{Mineralization Study}

Different quality assurance parameters like total organic carbon (TOC) and chemical oxygen demand (COD) were determined to study the mineralization efficiency following the standard protocols [30].

\section{Spectral Analysis}

The degradation products were characterized by Fourier-transform infrared spectroscopy (FTIR).

\section{Statistical Analysis}

All experiments were carried out in triplicate. The results were computed by measuring standard error of means [31].

\section{Results and Discussion}

\section{SEM Analysis}

For scanning electron microscopy (SEM) pictures, the scatterings were weakened with water and drop-cast onto a silicon wafer. The samples were dried under encompassing conditions. SEM was performed with an FEI Quanta 400 FEG outfitted with an auxiliary electron (SE) identifier. The size and morphology a)

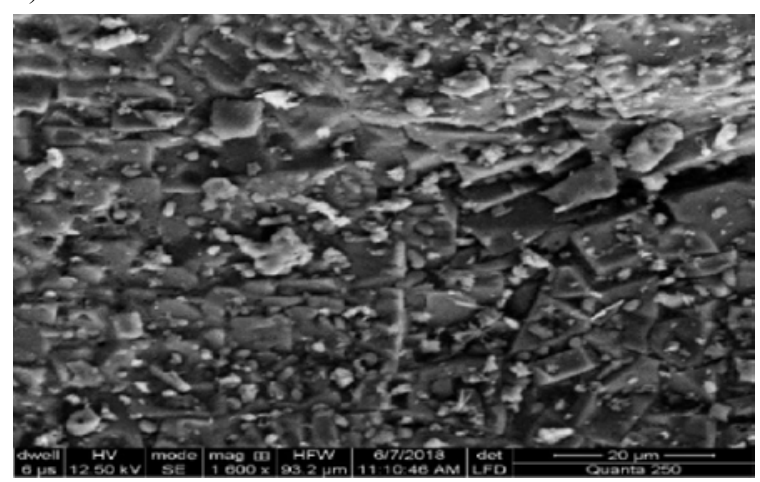

b)

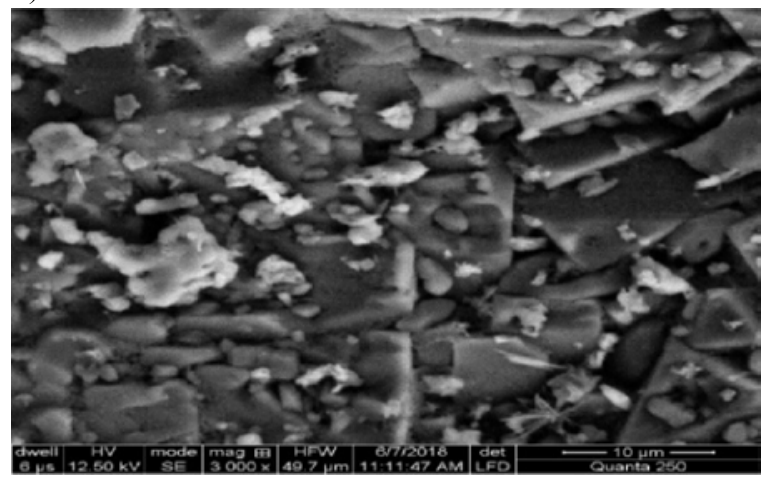

c)

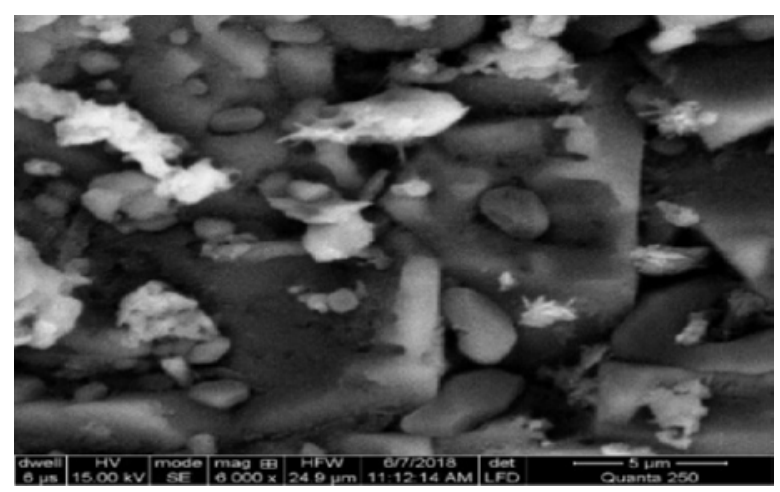

Fig. 1. a) SEM image of NPs from distance of $20 \mu \mathrm{m}$, b) SEM image of NPs from distance of $10 \mu \mathrm{m}, \mathrm{c})$ SEM image of NPs from distance of $5 \mu \mathrm{m}$.

of the synthesized Cu-NPs were analyzed by scanning electron microscopy (SEM). SEM images (Fig. 1a-c) revealed the synthesis of copper nanoparticles (Cu-NPs) using Labeo rohita fish scale extract as stabilizing and reducing medium. Particles appeared as spherical and crystalline, and some particles were in the form of clusters. These images were taken from 5, 10 and $20 \mu \mathrm{m}$. At $5 \mu \mathrm{m}$, the image was cleared and showed the formation of spherical NPs [32].

\section{Determining Size Distribution Intensity by Dynamic Light Scattering Method}

Refractive index of the material was found to be 2.63. Material absorption was 0.001 . The average particle size of synthesized copper nanoparticles was found to 


$\begin{array}{rlllll} & & & \text { Size (d.n... } & \% \text { Intensity: } & \text { St Dev (d.n... } \\ \text { Z-Average (d.nm): } & 1358 & \text { Peak 1: } & 805.8 & 100.0 & 99.92 \\ \text { Pdl: } & 0.323 & \text { Peak 2: } & 0.000 & 0.0 & 0.000 \\ \text { Intercept: } & 0.966 & \text { Peak 3: } & 0.000 & 0.0 & 0.000 \\ \text { Result quality } & \text { Refer to quality report } & & & \end{array}$

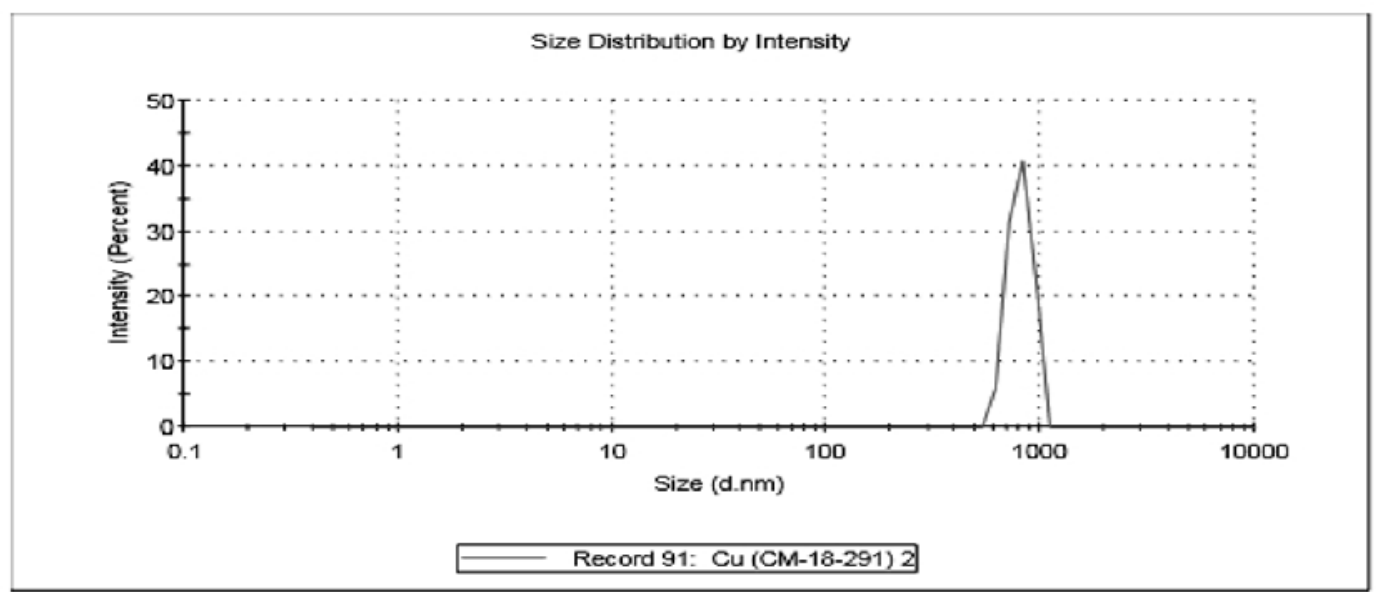

Fig. 2. Size distribution intensity of synthesized Cu-NPs.

be $1352 \mathrm{~nm}$. Particle size analysis showed the presence of nanoparticles with polydispersity index (PDI) value 0.323 and with intercept 0.966 (Fig. 2). The DLS method was found to be effective for studying the light scattering patters of different particles effectively [27].

\section{Determination of $\lambda_{\max }$}

To determine the wavelength of maximum absorbance, the absorbance over the range of $400-650 \mathrm{~nm}$ was measured, usually in interval of $25 \mathrm{~nm}$. The $\lambda_{\max }$ was found to be $425 \mathrm{~nm}$ as shown in Fig. 3.

\section{Optimizing Conditions for the Decolorization of Reactive Blue 19 dye}

Decolorization (\%) of Reactive Blue 19 dye was studied by optimizing the different experimental parameters, such as effect of concentration of dye, concentration of copper nanoparticles, $\mathrm{pH}$ and

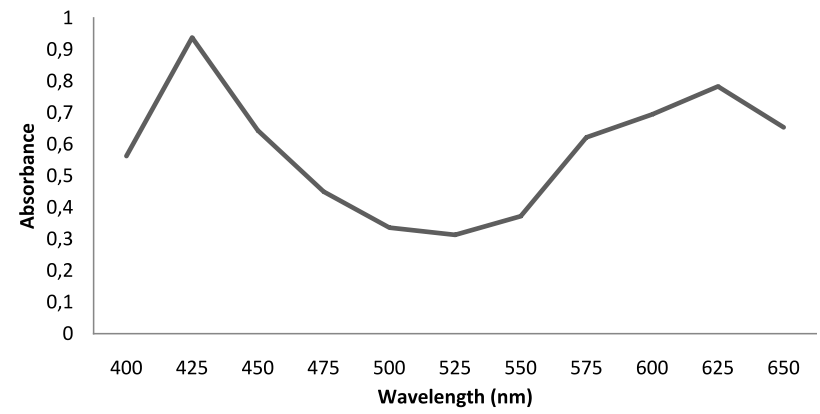

Fig. 3. Determining wavelength of maximum absorbance for Reactive Blue 19 dye. temperature to get optimized conditions for maximum decolorization of the dye under study.

\section{Effect of Dye Concentration}

Reaction was carried out with different concentrations $(0.01,0.03,0.05,0.07$ and $0.1 \%)$ of Reactive Blue 19 dye solutions for 75 minutes. As the concentration of dye solution was increased from 0.01 to $0.03 \%$, the decolorization (\%) was increased from $67.47 \%$ to $80.44 \%$. Further increase in concentration up to $0.1 \%$ resulted in a decrease in decolorization (Fig. 4). When initial concentration of a dye increased, there are more dye molecules to be broken up by the catalyst up to a saturation point. Further increases in concentration of dye molecules and degradation of dye may be retarded due to the hindrance caused by the metabolites formed during the reaction [33] or non-availability of a more catalytic surface to catalyze the reaction $[34,35]$.

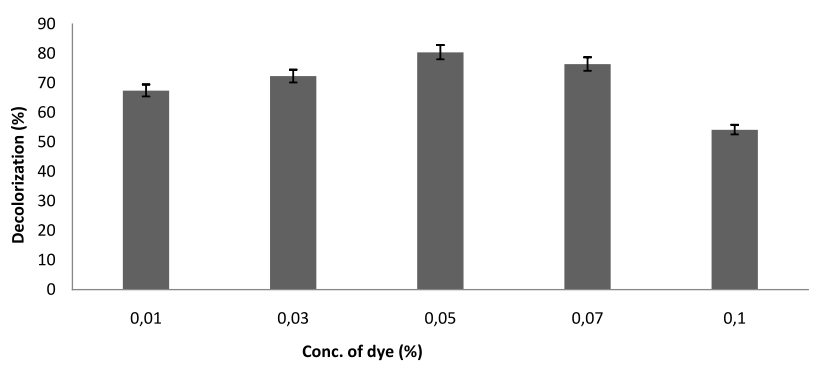

Fig. 4. Effect of concentration of Reactive Blue 19 dye on its decolorization (\%) using copper nanoparticles. 


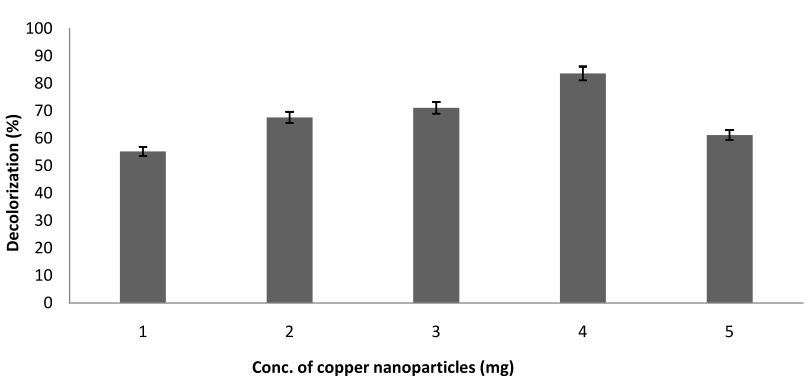

Fig. 5. Effect of concentration of copper nanoparticles on decolorization (\%) of Reactive Blue 19 dye.

\section{Effect of Concentration of Copper Nanoparticles $(\mathrm{Cu}-\mathrm{NPs})$}

It is known from previous studies that more number of nanoparticles result in the enhanced rate of dye removal, owing to the availability of more catalytic surfaces to be attacked on the chromophoric group of the target dye [30]. It could be seen from Fig. 5 that as the concentration of copper nanoparticles was increased from 1-4 mg, the decolorization of dye was increased from 65.43 to $83.65 \%$. A further increase in concentration of nanoparticles resulted in a decline in decolorization (\%), which might be due to the agglomeration or sedimentation of nanoparticles [11]. The greater the concentration of nanoparticles, the more the number of active sites of catalyst are to be attacked on the chromophoric group of the target dye. After a certain concentration, the decolorization of dye decreased due to saturation of catalytic surface or the formation of by products, which may act as inhibitors resulting in a decrease in decolorization efficiency of the catalyst. Increases in the photo-catalyst loading do not lead to significant higher decolorization efficiency. This may be due to the fact that at high catalyst concentrations, the catalyst particles inclined to accumulate, which decrease the catalytic action by reducing its specific surface area $[36,37]$.

\section{Effect of $\mathrm{pH}$}

$\mathrm{pH}$ is a very important parameter. A minor change in $\mathrm{pH}$ may result in a major change in reaction

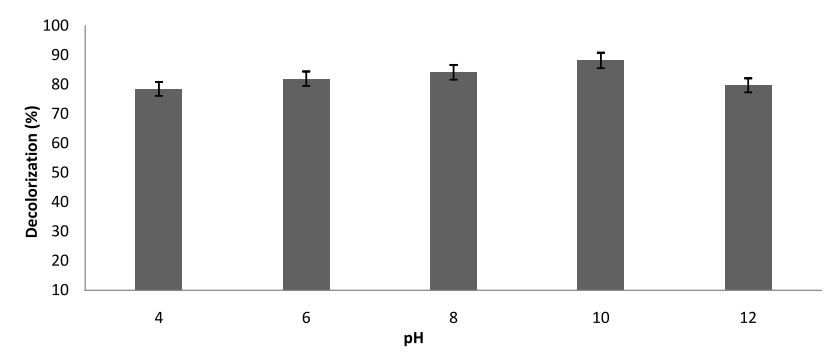

Fig. 6. Effect of pHon decolorization (\%) of Reactive Blue 19 dye using copper nanoparticles.

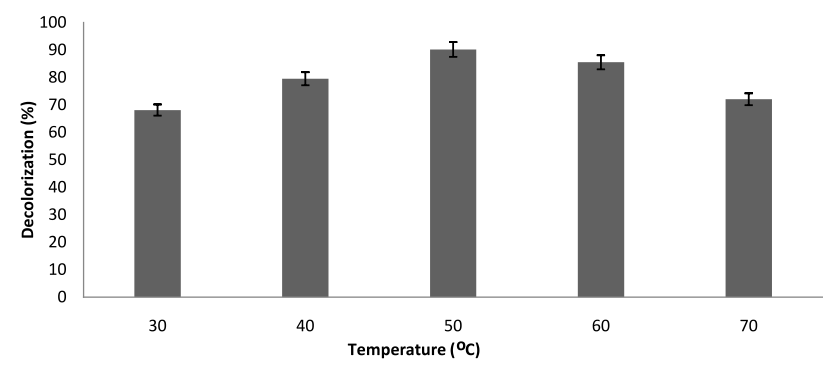

Fig. 7. Effect of temperature on decolorization (\%) of Reactive Blue 19 dye using copper nanoparticles.

rate. Hence its optimization is deemed necessary. $\mathrm{pH}$ varied between 4-12 and results are shown in Fig. 6. It was seen that decolorization (\%) increased with increases in $\mathrm{pH}$ up to 10 . A further increase in $\mathrm{pH}$ resulted in a decrease in decolorization (\%). Maximum decolorization was found to be $88.19 \%$ at $\mathrm{pH} 10$ (Fig. 6), which may be due to increased production rate of hydroxyl ions in basic medium. At low $\mathrm{pH}, \mathrm{H}^{+}$are greater than interacting with dye molecules and reduce the interaction of hydroxyl radical with dye [38]. $\mathrm{pH}$ of the solution is a complex factor since it is linked with the ionization state of the nanoparticle surface and that of the reactants and products [39]. At higher $\mathrm{pH}$, there is an enhanced repulsion between dye negative charges and nanoparticle anionic surface, which hinders molecules migration from the solution to the nanoparticle surface [40].

\section{Effect of Temperature}

Temperature is a crucial factor for the decolorization of dyes. Decolorization (\%) was studied at different temperatures ranging from $30-70^{\circ} \mathrm{C}$. Increases in temperature resulted in increases in decolorization (\%) of up to $50^{\circ} \mathrm{C}$. Maximum decolorization $(90.18 \%)$ was obtained at $50^{\circ} \mathrm{C}$ (Fig. 7). The increase in decolorization (\%) with increase in temperature may be due to increases in binding sites of the catalyst. As binding sites increased, decolorization (\%) also increased. Moreover, as the temperature increases, oxidation rate of dye also increases, but after a particular temperature the catalytic efficiency is retarded [41].

\section{Effect of Reaction Time}

Reaction was carried out for 75 minutes. Maximum decolorization (\%) was achieved at 60 minutes (Fig. 8). Thus, it can be concluded that with the passage of time, decolorization (\%) increases up to 60 minutes and after 60 minutes it decreases [9].

\section{FTIR Analysis}

An FTIR study was carried out to describe the products generated as a result of degradation of Reactive Blue 19 dye. Comparison among FTIR spectra 


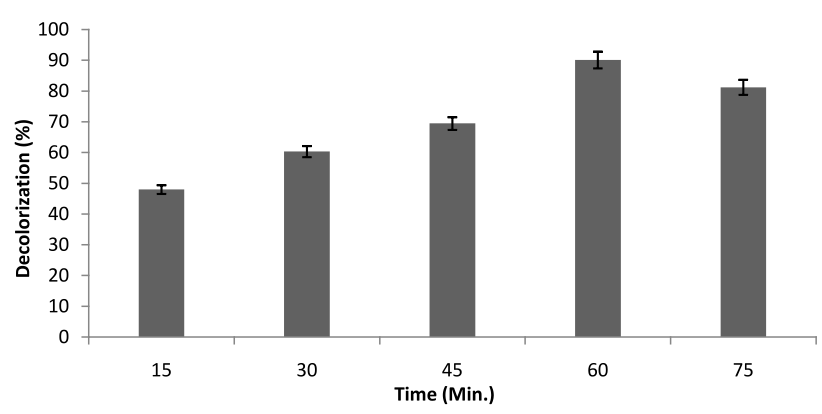

Fig. 8. Effect of reaction time on the decolorization (\%) of Reactive Blue 19 dye using copper nanoparticles.

of untreated dye solution with treated indicated the degradation of dye when it was subjected to catalytic treatment. FTIR spectrum of untreated Reactive Blue 19 dye exhibited peaks at 3344.59, 2352.21, 1646.3, 619.15 and $613.956 \mathrm{~cm}^{-1}$ for $-\mathrm{OH}$ stretch of phenol, $\mathrm{N}=\mathrm{N}$ stretch and $\mathrm{C}=\mathrm{C}$ stretching of monosubstituted benzene ring (Fig. 9a), whereas treated dye solution displayed peaks at $3295.81 \mathrm{~cm}^{-1}$ for $-\mathrm{OH}$ stretch due to the presence of $-\mathrm{COOH}$ group, $2941.08 \mathrm{~cm}^{-1}$ and $2825.79 \mathrm{~cm}^{-1}$ for $\mathrm{C}-\mathrm{H}$ stretching of alkyl benzene,
$2351.33 \mathrm{~cm}^{-1}$ for $=\mathrm{C}-\mathrm{H}$ stretch, $1739.42 \mathrm{~cm}^{-1}$ for -C-H deformation, $1460.07 \mathrm{~cm}^{-1}$ for $-\mathrm{C}-\mathrm{H}$ bending, 1251.66 and $1025.52 \mathrm{~cm}^{-1}$ for $\mathrm{C}-\mathrm{O}$ stretch in $-\mathrm{COOH}$ group, 604.28 and $657.49 \mathrm{~cm}^{-1}$ for monosubstituted benzene ring (Fig. 9b). There were no peaks in the region of 3400 to $3380 \mathrm{~cm}^{-1}$ specified by the absence of a mines when our dye was exposed to catalytic treatment using $\mathrm{Cu}-\mathrm{NPs}$. FTIR spectral analysis indicated that decolorization of dye under study was due to degradation of dye into intermediate products. Distinctive peak of azo linkage at $1646.3 \mathrm{~cm}^{-1}$ was not there, signifying breakage of Reactive Blue 19 dye. Aromatic a mines were formed during the reaction as intermediate ones, which were exposed to oxidation, giving the simplest mixes. Our results are in accordance with the literature [42].

\section{Mineralization Study}

Analysis of quality assurance parameters like chemical oxygen demand (COD) and total organic carbon (TOC) of treated samples were carried out to find out their mineralization efficiency. Reduction (\%) in COD and TOC was observed with the increase a)
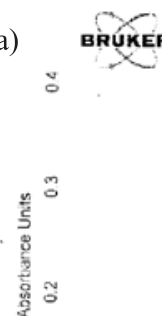

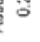

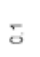

5
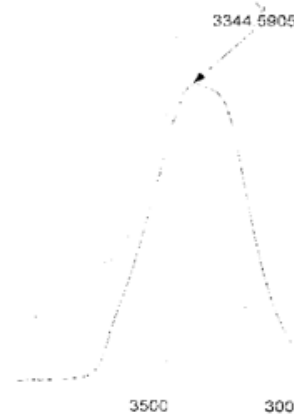

33445905

b)
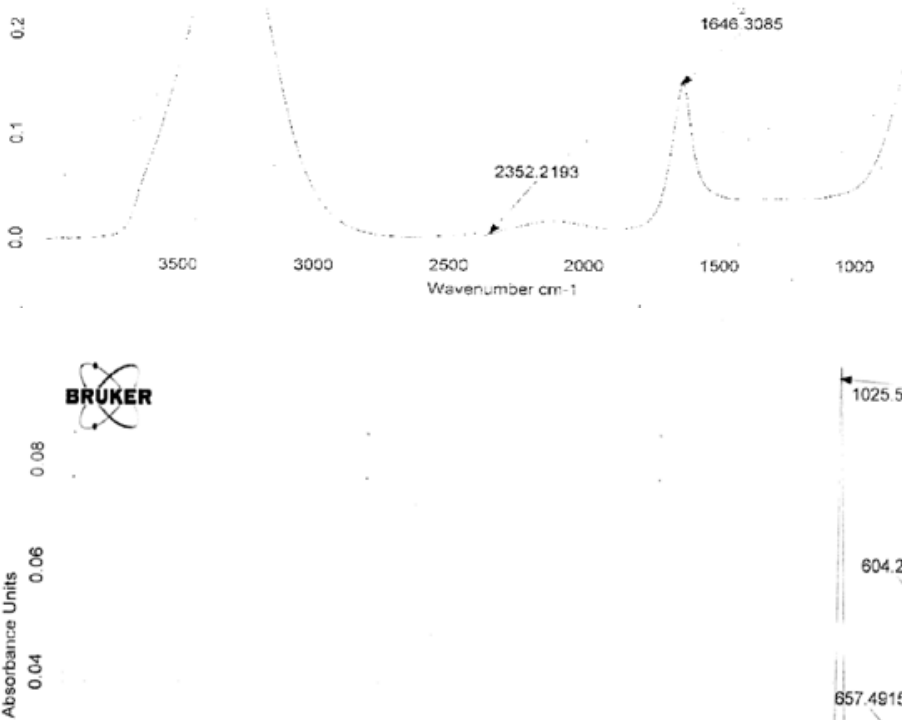

ชั0

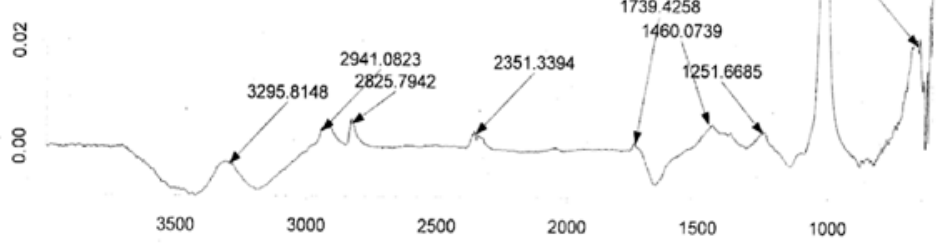

Fig. 9. a) FTIR spectrum of reactive dye 222 before catalytic treatment, b) FTIR spectrum of reactive dye 222 after catalytic treatment. 


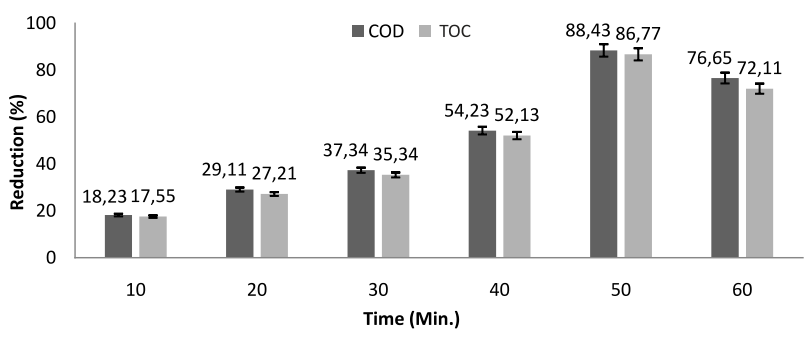

Fig. 10. Effect of reaction contact time on water quality parameters.

in reaction contact time from 10 to 50 minutes. The maximum reduction (\%) in COD and TOC obtained at 50 min. were $88.23 \%$ and $86.77 \%$, respectively (Fig. 10). Reduction (\%) of COD and TOC with the progressive rise in time depicted the mineralization of dye under study [9]. It can be inferred that copper nanoparticles not only decolorize the Reactive Blue 19 dye but also reduce the $\mathrm{COD}$ and TOC, indicating degradation of the dye [42].

\section{Conclusions}

The developed method was found to be green, environmental friendly and economical. The current study was done to investigate the decolorization of Reactive Blue 19 using copper-NPs synthesized by green route. Maximum decolorization (\%) was found to be $92.52 \%$ under optimized experimental conditions. The findings of the current study showed that these synthesized copper NPs could be applied for decolorization of Reactive Blue 19. Thus, notorious dyes and industrial effluents containing these dyes can be detoxified using copper NPs. The study found that without using any chemical reagent as stabilizing and reducing agents, the copper nanoparticles are stable. Hence this cost-effective and eco-friendly method is highly promising for future.

\section{Acknowledgments}

The authors are thankful to the Department of Applied Chemistry, GCUF for use of their lab facility and elaboration of results.

\section{Conflict of Interest}

All authors declare no conflict of interest.

\section{References}

1. SAFAVI A., MOMENI S. Highly efficient degradation of azo dyes by palladium/hydroxyapatite $/ \mathrm{Fe}_{3} \mathrm{O}_{4}$ nanocatalyst. J. Hazard Mater. 201, 125, 2012.
2. CHAKRABORTY S., PURKAIT M.K., DASGUPTA S., DE S., BASU J.K. Nanofiltration of textile plant effluent for color removal and reduction in COD. Sep. Purif. Technol. 31, 141, 2003.

3. NIDHEESH P.V., GANDHIMATHI R., RAMESH S.T. Degradation of dyes from aqueous solution by Fenton processes: a review. Environ. Sci. Poll. Res. 20, 2099, 2013.

4. PANIC V.V., SESLIJA S.I., NESIC A.R.,VELICKOVIC S.J. Adsorption of azo dyes on polymer materials. Hem. Ind. 67, 881, 2013.

5. RASHID A., NOSHEEN S.,Kiran S., BHATTI H.N., KAMAL S., SHAMIM F., RAFIQUE M.A. Combination of oxidation and coagulation processes for wastewater decontamination on batch scale. Oxid. Commun. 39, 1716, 2016.

6. KIRAN S., ADEEL S., NOSHEEN S., HASSAN A., USMAN M., RAFIQUE M.A. Recent trends in textile effluent treatments: A review. Adv. Mater. Wastewater Treat. 29, 2017.

7. GULZAR T., HUMA T., JALAL F., IQBAL S., ABRAR S., KIRAN S., RAFIQUE M.A. Bioremediation of synthetic and industrial effluents by Aspergillus niger isolated from contaminated soil following a sequential strategy. Molecules 22, 2244, 2017.

8. CHAKRABORTY S., CHOWDHURY S., SAHA P.D. Fish (Labeo rohita) scales as a new biosorbent for removal of textile dyes from aqueous solutions. J. Water Reuse Desalin. 2, 175, 2012.

9. KIRAN S., ALI S.,ASGHER M., SHAHID S.A. PhotoFenton process: Optimization and decolourization and mineralization of reactive blue 222 dye. J. Environ. Sci. Water Resour. 1, 267, 2012.

10. LIANG C.Z., SUN S.P., LI F.Y., ONG Y.K., CHUNG T.S. Treatment of highly concentrated wastewater containing multiple synthetic dyes by a combined process of coagulation/flocculation and nanofiltration. J. Memb. Sci. 469, 306, 2014.

11. WANG H., SUN F., ZHANG Y., LI L., CHEN H., WU Q., JIMMY C.Y. Photochemical growth of nanoporous $\mathrm{SnO}_{2}$ at the air-water interface and its high photo-catalytic activity. J. Mater. Chem. 20, 5641, 2010.

12. UZUNOGLU D., OZER A. Adsorption of Acid Blue 121 dye on fish (Dicentrarchus labrax) scales, the extracted from fish scales and commercial hydroxyapatite: equilibrium, kinetic, thermodynamic, and characterization studies. Desalin. Water Treat. 57, 14109, 2016.

13. KAUR R., DUA A. Acute toxicity, behavioural and morphological alterations in Indian carp, Labeo rohita on exposure to municipal wastewater of Tung D hab drain, Punjab, India. Int. J. Sci. Res. 3, 1716, 2014.

14. CHOWDHURY S., CHAKRABORTY S., SAHA P. Biosorption of Basic Green 4 from aqueous solution by Ananas comosus (pineapple) leaf powder. Colloids Surf. Biointerfaces 84, 520, 2011.

15. CHOWDHURY S., SAHA P. Sea shell powder as a new adsorbent to remove Basic Green 4 (Malachite Green) from aqueous solutions: Equilibrium, kinetic and thermodynamic studies. Chem. Eng. J. 164, 168, 2010.

16. NASEER A., NOSHEEN S., KIRAN S., KAMAL S., JAVAID M.A., MUSTAFA M., TAHIR A. Degradation and detoxification of Navy Blue CBF dye by native bacterial communities: an environmental bioremedial approach. Desalin. Water Treat. 57, 24070, 2016.

17. ISLAM M.S., KHAN S., TANAKA M. Waste loading in shrimp and fish processing effluents: potential source of 
hazards to the coastal and near shore environments. Mar. Pollut. Bull. 49, 103, 2004.

18. BHAGWAT P.K., DANDGE P.B. Isolation, characterization and valorizable applications of fish scale collagen in food and agriculture industries. Biocatal. Agri. Biotechnol. 7, 234, 2016.

19. KUMARI S., RATH P., KUMAR A.S.H. Chitosan from shrimp shell (Crangon crangon) and fish scales: Extraction and characterization Suneeta. Afr. J. Biotechnol. 15, 1258, 2016.

20. JEONG S., SONG H.C., LEE W.W., LEE S.S., CHOI Y., SON W., RYU B.H. Stable aqueous based $\mathrm{Cu}$ nanoparticle ink for printing well-defined highly conductive features on a plastic substrate. Langmuir 27, 3144, 2011.

21. FISSAN H., RISTIG S., KAMINSKI H., ASBACH C., EPPLE M. Comparison of different characterization methods for nanoparticle dispersions before and after aerosolization. Anal. Meth. 6, 7324, 2014.

22. HUANG C.C., LO L.S., LIEN H.L. Zero-valent copper nanoparticles for effective dechlorination of dichloromethane using sodium borohydride as reductant. Chem. Engng. J. 203, 95, 2012.

23. DUTTA S., SAHA R., KALITA H., BEZBARUAH A.N. Rapid reductive degradation of azo and anthraquinone dyes by nanoscale zero-valent iron. Environ. Technol. Innovation 5, 176, 2016.

24. DONG F., LI Q., SUN Y., HO W.K. Noble metal-like behavior of plasmonic $\mathrm{Bi}$ particles as a co-catalyst deposited on $(\mathrm{BiO})_{2} \mathrm{CO}_{3}$ microspheres for efficient visible light photo-catalysis. Amer. Chem. Soc. Catal. 4, 4341, 2014.

25. HE Y., GAO J.F., FENG F.Q., LIU C., PENG Y.Z., WANG S.Y. The comparative study on the rapid decolorization of azo, anthraquinone and triphenyl methane dyes by zerovalent iron. Chem. Engng. J. 179, 8, 2012.

26. WEN G., WANG S.J., MA J. Oxidative degradation of organic pollutants in aqueous solution using zero valent copper under aerobic atmosphere condition. J. Hazard. Mater. 275, 193, 2014.

27. UMOREN S.A., OBOT I.B., GASEM Z.M. Green synthesis and characterization of silver nanoparticles using red apple (Malus domestica) fruit extract at room temperature. J. Mater. Environ. Sci. 5, 907, 2014.

28. SINHA T., AHAMARUZZAMAN M. High-value utilization of egg shell to synthesize silver and goldsilver core shell nanoparticles and their application for the degradation of hazardous dyes from aqueous phase-A green approach. J. Colloid interface Sci. 453, 115, 2015.

29. CHATHA S.A.S., KIRAN S., GULZAR T., KAMAL S., GHAFFAR A., CHATHA M.N. Comparative study on decolorisation and mineralization of synthetic and real textile effluents using advanced oxidation processes. Oxid. Commun. 39, 1604, 2016.

30. GREENBERG A.E., TRUSSELL R.L., CLESCERI L.S. Standard Methods for the examination of water and wastewater. $20^{\text {th }}$ Ed., 38, 1985.
31. STEEL R.G., TORRIE J.H., DICKEY D.A. Principles and procedures of Statistics: A Biochemical Approach, $3^{\text {rd }}$ Ed., McGraw Hill, New York, USA, 271, 1997.

32. KIRAN S., ALI S., ASGHER M. Degradation and mineralization of azo dye reactive blue 222 by sequential photo-Fenton's oxidation followed by aerobic biological treatment using white rot fungi. Bull. Environ. Contam. Toxicol. 90, 208, 2013

33. SINHA T., AHMARUZZAMAN M. A novel green and template free approach for the synthesis of gold nanorice and its utilization as a catalyst for the degradation of hazardous dye. Spectrochimica Acta A Mol. Biomol. Spectrosc. 142, 266, 2015.

34. SINGH H.K., SAQUIB M., HAQUE M.M., MUNEER $\mathrm{M}$. Heterogeneous photo-catalyzed decolorization of two selected dye derivatives neutral red and toluidine blue in aqueous suspensions. Chem. Engng. J. 136, 77, 2008.

35. DIXIT A., MUNGRAY A.K., CHAKRABORTY M. Photochemical oxidation of phenol and chloro-phenol by $\mathrm{UV} / \mathrm{H}_{2} \mathrm{O}_{2} / \mathrm{TiO}_{2}$ process: A kinetic study. Int. J. Chem. Engng. Applicatitions, 1, 2010, 2010.

36. MARCELO C.R., PUIATTI G.A., NASCIMENTO M.A., OLIVEIRA A.F., LOPES R.P. Degradation of the Reactive Blue 4 dye in aqueous solution using zero-valent copper nanoparticles. J. Nanomaterials 1, 2018.

37. SELVAKUMAR S., MANIVASAGAN R., CHINNAPPAN $\mathrm{K}$. Biodegradation and decolourization of textile dye wastewater using Ganoderma lucidum. Biotech. 3, 71, 2013.

38. YU Z., WEN X. Screening and identification of yeasts for decolorizing synthetic dyes in industrial wastewater. Int. Biodeter. Biodegr. 56, 109, 2005.

39. KIRAN S., NOSHEEN S., IQBAL S., ABRAR S., JALAL F., GULZAR T., MUKHTAR, A., MAQSOOD S., AHMAD W., NASEER N. Photo-catalysis using titanium dioxide for treatment of textile wastewater containing disperse dyes. Chiang Mai J. Sci. 45, 2730, 2018.

40. GULZAR T., KIRAN S., ABRAR S., RAHMAT M., HAQUE A., NOSHEEN S., AHMAD A., RASUL S. Role of Enzymatic System of Screened Pleurots ostreatus IBL-02 in the Bio-Removal of Synthetic Dyes Effluent. J. Chem. Soc. Pak. 41, 509, 2019.

41. KIRAN S., HUMA T., JALAL F., FAROOQ T., HAMEED A., GULZAR T., BASHIR A., RAHMAT M. RAHMAT R., RAFIQUE M.A. Lignin Degrading System of Phanerochaete chrysosporium and its Exploitation for Degradation of Synthetic Dyes Wastewater. Pol. J. Environ. Stud. 28, 1749, 2019.

42. KIRAN S., GULZAR T., IQBAL S., HABIB N., HASSAN A., NAZ S. Valorization of Wastes for the Remediation of Toxicants from Industrial Wastewater. Integr. Green Chem. Sustain. Engng. 473, 2019. 